\title{
Causative Relationship Between Drug Abuse And Sexual Dysfunction in Males.
}

\author{
Soheir A. Mohammed, MD ${ }^{1}$; Amr Abdelhamed, MD, FECSM ${ }^{2 *}$; \\ Reda M. El Sayed, MD ${ }^{1}$, Mohammed H. Mohammed. \\ ${ }^{1}$ Forensic Medicine \& Clinical Toxicology Department, Faculty of Medicine, \\ Sohag University, Egypt. \\ ${ }^{2}$ Dermatology, Venereology and Andrology Department, Faculty of Medicine, \\ Sohag University, Egypt.
}

\section{Abstract}

Objectives: Most studies investigate sexual dysfunction in drug abusers. However, no data is available about drug abuse in patients with sexual dysfunction especially in Upper Egypt. Therefore, this study aims to assess the pattern of drug abuse in patients with sexual dysfunction, and its potential impact on hormonal profile .

Material and Methods: The study included 100 male patients with history of sexual dysfunction for at least 6 months. Initial evaluation with history, general \& local examinations were done. Sexual dysfunction was evaluated with the Arabic version of Sexual health inventory for men (SHIM), Erection hardness score (EHS), and the Arabic Index of Premature Ejaculation (AIPE). Morning blood sample was used for assessment of Total Testosterone (TT), Luteinizing Hormone (LH), and Follicle Stimulating Hormone (FSH). Urine sample was screened by (ABON ${ }^{\mathrm{TM}}$ Multi-Drug) dipstick kits for the following drug abuse tramadol, opiate, THC (Cannabis), amphetamine, barbiturate, cocaine and benzodiazepines. Positive results were confirmed by the Immunoassay drug analyzer through the use of specific antibodies.

Results: Patients' characteristics showed age 39 (31-45) years with 52\% were smoker. Sexual dysfunction complaints included PE (76\%), ED (57\%), and combined (43\%), with average duration of 11 (8-18) months. Patients' hormonal profile showed TT 6.3 (2.67-7.55) ng/ml, FSH 3.5(1.86-5.01) $\mathrm{mIU} / \mathrm{ml}$, and LH 3.1(2.1-5) $\mathrm{mIU} / \mathrm{ml}$. SHIM, EHS, and AIPE were 15 (1219), 3 (2-3), and 19(16-24) respectively. Urine screening was positive in $39 \%$ (39/100). Confirmation by drug analyzer revealed 4 patients were false positive. Therefore, the final result for drug abuse was 35\% (35/100); with the most common drug was tramadol 19\% (19/100) followed by THC (Cannabis) 12\% (12/100). Patients with positive drug abuse had significantly higher smoking percent $(\mathrm{p}=<0.0001)$, higher driver occupation $(\mathrm{p}=0.018)$, and higher positive drug abuse history $(\mathrm{p}=<0.0001)$. There were no significant changes in both the sexual dysfunction severity and hormonal profile between positive and negative drug abuse groups. Through binary logistic regression, both smoking (OR=22.39, 95\% CI: 4.20- 119.19, $\mathrm{p}=<0.0001)$, and history of drug abuse $(\mathrm{OR}=20.26,95 \%$ CI: $5.21-78.76, \mathrm{p}=<0.0001)$ are significantly independent predictors for positive drug abuse test.

Conclusions: Drug abuse is prevalent among Egyptian male patients with sexual dysfunction, especially tramadol. The drug abuse is common among smoker, and driver occupation. However, no hormonal disturbance could be shown in drug abuse patients. More patient awareness and legal regulations should be considered to reduce drug abuse in Egypt.

Key words: Sexual dysfunction, Drug abuse.

\section{Introduction}

Drug abuse is defined by the harmful or hazardous use of psychoactive substances, including alcohol and illicit drugs. The repeated use of these psychoactive substances can lead to dependence syndrome, which leads to strong desire to have the drug, inability to control its use, and continue its use despite negative consequences (WHO, 2010). In Egypt, 
drug abuse is considered a serious health problem due to its spread among youth, with the tramadol is commonest drug and cigarette smoking with marijuana is the commonest practice (lofferdo CA, et al.2015)

Although many patients with sexual dysfunction are often using illicit drugs as aphrodisiacs for enhancement of their sexual performance, the current data suggest the negative impact of most of these illicit drugs on sexual functions (Kumsar NA,et al 2016). High rates of sexual dysfunction has been reported in opioid addicts 34$85 \%$. The long term opioid can impair all sexual domains in males; with ED and $\mathrm{PE}$ are the commonest ones (Ajo $R$, et al, 2016). Also, it seems that cannabis may impair erectile function in animal and in vitro studies (Samloul $R, 2011$ )

However, most studies are focusing on evaluating sexual dysfunctions in drug abusers and no data available about screening drug abuse in male patients with sexual dysfunction. Therefore, this study is designed to assess the pattern of drug abuse in patients with sexual dysfunction. In addition, identify correlation between drug abuse and sexual dysfunction, and evaluate the male hormonal profile in patients with drug abuse.

The Aim of the study

This present study aims to

- Identify the pattern of drug abuse among male patients with sexual dysfunction including proportion and the commonest drug/drugs of abuse.

- Evaluate the relationship between type and severity of male sexual dysfunction and drug abuse.

- Evaluate the impact of drug abuse on the male sex hormones in patients with sexual dysfunction.

Patients and methods

Study design
A prospective cross-sectional study was conducted on (100) male patients with sexual dysfunction seeking medical advice at Andrology outpatient clinic, Sohag University Hospital, Sohag, Egypt in the period from January 2017 to January 2018. The study design was approved by the ethical and scientific research committee of Sohag University. Written informed consent was obtained from all patients. The study included male patients between (18-55 years old) with history of any type of sexual dysfunction for at least 6 months. Patients with the following conditions were excluded: diabetes mellitus, hypertension, history of advanced kidney or liver diseases, history of chronic pain, history of endocrine disorders including hypogonadism, history of psychotropic medications for one month prior to the study.

Methodology

I. Initial evaluation:

History taking of sexual dysfunction patients included personal history, special habits, drug treatment and sexual history. General examination included body weight, height, and BMI, followed by genital examination.

II. Sexual dysfunction evaluation:

All sexual dysfunctions were evaluated including disorders of desire, erection, ejaculation, and orgasm. The following questionnaires were used as follows:

II-A- Sexual Health Inventory for Men (SHIM) Questionnaire:

Over the last 6 months, the erectile function of the patient was evaluated by the Arabic version of SHIM questionnaire. The total score of responses to each of the five items on the SHIM can range from 1 to 25, with higher scores indicating better sexual health. Patients with a score of $\leq 21$ may have evidence of ED. According to SHIM score, ED patients were divided to mild (17-21), mild to 
moderate (12-16), Moderate (8-11), and Severe (1-7) (Shamloul et al., 2004).

II-B- Erection Hardness score (EHS):

Patients were evaluated by EHS. The EHS is a validated self-reported measure that classifies erection hardness on a single-item scale. According to EHS, ED patients were graded to optimal erection (4), suboptimal erection (3), moderate ED (2), and severe ED $(\leq 1)$ (Mulhall et al., 2007).

II-C- Arabic Index of Premature Ejaculation (AIPE):

It is a validated diagnostic tool for PE. The total score of responses to each of the seven items on the AIPE can range from 1 to 35, with lower scores indicating severe PE. According to AIPE, PE severity was classified into five categories; severe (7-13), moderate (14-19), mild to moderate (20-25), mild (26-30), and no PE (3135) (Arafa\&Shamloul, 2007).

III. Laboratory investigations:

III-A- Screening for drug abuse in urine specimen:

III- A- 1. Rapid dipstick:

Screening tests for drug abuse in urine samples was performed by dipstick named (ABON ${ }^{\mathrm{TM}}$ Multi-Drug) which is one step screen test panel used for qualitative detection of drugs of abuse which includes (Tramadol, Opiate, THC, Amphetamine, Cocaine, Barbiturate, Benzodiazepines)

\section{Results}

The study included 100 patients with sexual dysfunction with median age 39 (31-45) years old. More than half $(52 \%)$ of patients were smoker, with no history of alcohol intake. The most common sexual complaint was PE (76\%) followed by ED (57\%); with average of sexual complaint duration was 11 (8-18) months. Patients with positive history of drug abuse were $43 \%$, with average drug abuse duration 5 (3-6.25) years. All patients had a normal genital examination. Patients' hormonal profile showed TT 6.3 (2.67-7.55) ng/ml, FSH 3.5(1.86-5.01) $\mathrm{mIU} / \mathrm{ml}$, and LH 3.1(2.1-5) $\mathrm{mIU} / \mathrm{ml}$. Sexual function evaluation of patients was as follows, SHIM score 15 (1219), EHS 3 (2-3), and AIPE 19(16-24). All data related to the patients' characteristics including history, general examination and laboratory investigations was summarized in Table (1).
III- A- 2. Confirmation by the drug analyzer:

Positive results were confirmed by the immunoassay drug analyzer (CDx90,Thermo Fisher Scientific Co, Supplier AMG Company). Analysis was carried out at the Clinical Toxicological Laboratory, Sohag University Hospital, Sohag, Egypt.

III-B-Hormonal assessment:

Morning blood sample was withdrawn at (8:00-10:00 am) in plain tubes. The samples centrifuged at $3500 \mathrm{rpm}$ for 5 minutes to obtain serum for hormonal assessment including Total Testosterone (TT), Luteinizing Hormone (LH), and Follicle Stimulating Hormone (FSH). Serum samples were tested on MINIVIDAS apparatus (bioMérieux Clinical Diagnostics) to measure the needed hormones. It is a compact automated immunoassay system based on the Enzyme Linked Fluorescent Assay (ELFA) principle.

Statistical analysis:

Data collected on a standard form, including all the variables listed before, were fed into a data collection sheet and then statistically analyzed. The obtained results were revised, coded and organized for statistical analysis using SPSS (Statistical package for Social Science) version 22 software. Data were presented and suitable analysis was done according to the type of data obtained for each parameter. 
SOHAG MEDICAL JOURNAL Causative Relationship Between Drug Abuse And

Vol. 22 No.2 July 2018

Mohammed H. Mohammed

Table 1: Clinical and laboratory patients' characteristics $(n=100)$.

\begin{tabular}{|c|c|c|}
\hline Parameter & $\begin{array}{l}\text { Mean } \pm \text { SD/ Median (25th-75th) or } \\
\text { percentage }\end{array}$ & Range \\
\hline \multicolumn{3}{|l|}{ History: } \\
\hline Age (Years) & $39(31-45)$ & $22-55$ \\
\hline Smoking (\%) & $52 \%$ & \\
\hline - $\quad$ Smoking history (years) & $14.5(11.25-20)$ & $5-33$ \\
\hline - $\quad$ Cigarette/day & $20(15-30)$ & $10-40$ \\
\hline - $\quad$ Brinkman smoking index & $300(202.5-510)$ & $90-1320$ \\
\hline 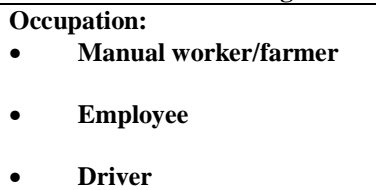 & $\begin{array}{l}53 \% \\
33 \% \\
14 \%\end{array}$ & \\
\hline \multicolumn{3}{|l|}{ Sexual history: } \\
\hline Marriage duration (years) & $10(5-16)$ & $1-26$ \\
\hline \multicolumn{3}{|l|}{ Patients sexual complaint: } \\
\hline $\begin{array}{ll}- \text { Desire problem } \\
\text { complaint }\end{array}$ & $7 \%$ & \\
\hline $\begin{array}{ll} & \text { Erectile dysfunction } \\
\text { complaint }\end{array}$ & $57 \%$ & \\
\hline $\begin{array}{ll}-\quad & \text { Premature } \\
\text { ejaculation complaint }\end{array}$ & $76 \%$ & \\
\hline $\begin{array}{ll} & \text { Orgasmic disorder } \\
\text { complaint }\end{array}$ & $17 \%$ & \\
\hline $\begin{array}{ll} & \begin{array}{l}\text { Mixed sexual } \\
\text { dysfunction } \\
\text { complaint }\end{array} \\
\end{array}$ & $43 \%$ & \\
\hline $\begin{array}{l}\text { Sexual complaint duration } \\
\text { (months) }\end{array}$ & $11(8-18)$ & 6-108 \\
\hline Frequency of intercourse/week & $2(2-3)$ & $1-4$ \\
\hline Wife age (years) & $33.29 \pm 7.47$ & $18-48$ \\
\hline \multicolumn{3}{|l|}{ Drug abuse history : } \\
\hline Positive drug abuse history & $43 \%$ & \\
\hline Drug abuse duration (years) & $5(3-6.25)$ & $1-20$ \\
\hline $\begin{array}{cl}\text { Route of drug administration: } \\
\bullet & \text { Oral } \\
\bullet & \text { Inhalation } \\
\bullet & \text { Oral/Inhalation }\end{array}$ & $\begin{array}{l}54.8 \% \\
23.8 \% \\
21.4 \%\end{array}$ & \\
\hline $\begin{aligned} & \text { Types of drug abuse: } \\
& \bullet \text { Tramadol } \\
& \bullet \text { THC } \\
& \bullet \text { Opiates } \\
& \bullet \text { Benzodiazepines }\end{aligned}$ & $\begin{array}{l}25 \% \\
19 \% \\
9 \% \\
4 \%\end{array}$ & \\
\hline $\begin{array}{l}\text { History of hospital admission } \\
\text { due to drug abuse }\end{array}$ & $7.3 \%$ & \\
\hline \multicolumn{3}{|l|}{ General examination: } \\
\hline Weight (Kg) & $79.07 \pm 10$ & $63-100$ \\
\hline Height (M) & $1.66 \pm 0.05$ & 1.58-1.80 \\
\hline BMI (Kg/m2) & $23.63 \pm 2.37$ & $19.94-27.78$ \\
\hline \multicolumn{3}{|l|}{ Hormonal profile: } \\
\hline $\begin{array}{ll}- & \begin{array}{l}\text { Total testosterone (TT) } \\
(\mathrm{ng} / \mathrm{ml})\end{array} \\
\end{array}$ & $6.3(2.67-7.55)$ & $0.22-9.67$ \\
\hline • $\quad$ LH $(\mathrm{mIU} / \mathrm{ml})$ & 3.1(2.1-5) & $0.21-7.13$ \\
\hline • $\quad$ FSH $(\mathrm{mIU} / \mathrm{ml})$ & 3.5(1.86-5.01) & 0.23-17.30 \\
\hline \multicolumn{3}{|l|}{ Sexual function evaluation: } \\
\hline SHIM score & $15(12-19)$ & $5-24$ \\
\hline EHS & $3(2-3)$ & $1-3$ \\
\hline AIPE & $19(16-24)$ & $12-30$ \\
\hline
\end{tabular}


After using the dipsticks for drug abuse screening in urine, $39 \%(39 / 100)$ of the patients were positive for drug abuse. All positive drug abuse results were confirmed by the drug analyser. The false postive results were $10.25 \%$ (4/39), and the final result for drug abuse was 35\% (35/100). The percentage of different types of drug abuse in all patients was showed in Figure. 1.

$\mathrm{SD}=$ Standard deviation; $\mathrm{THC}=$ Tetrahydrocannabinol; BMI=body mass index; $\mathrm{LH}=$ luteinizing hormone; FSH=follicle stimulating hormone, SHIM=sexual health inventory for men, EHS=erection hardness score, AIPE= Arabic index of premature ejaculation.

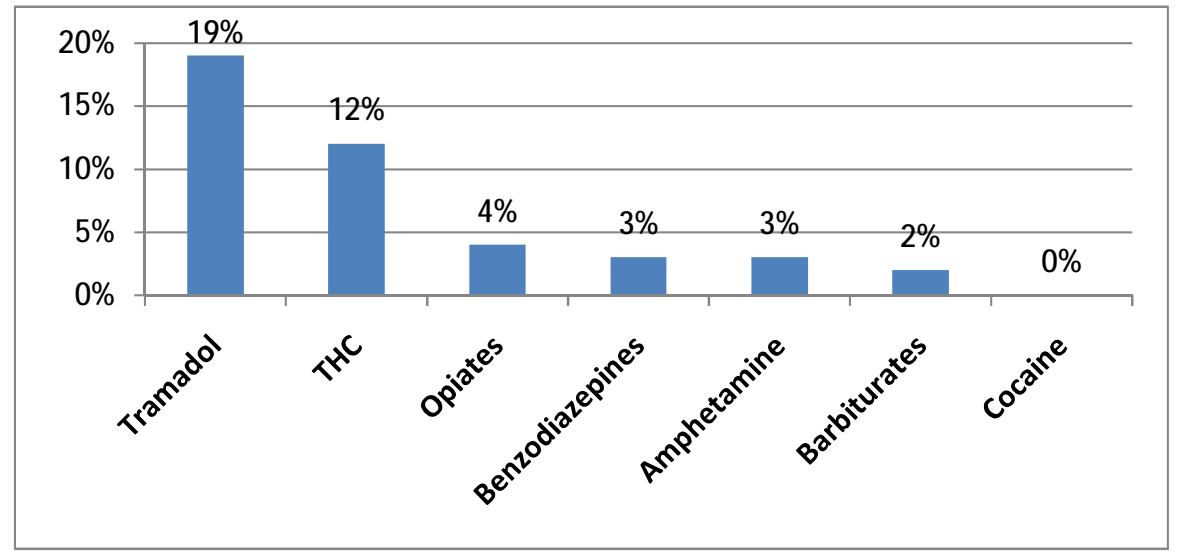

Figure 1: The result of drug abuse by urine testing in patients with sexual dysfunction $(n=100)$..

With analysis of positive drug abuser patients $(n=35)$, most of patients were single drug abuser $77.14 \%(27 / 35)$. The most common drug was tramadol 19\% (19/100) followed by THC $12 \%$ (12/100). Patients with positive drug abuse had significantly higher smoking percent $(\mathrm{p}=<0.0001)$, higher driver occupation $(\mathrm{p}=0.018)$, and higher positive drug abuse history $(\mathrm{p}=<0.0001)$ in comparison to patients with negative drug abuse. There were no significant changes in both the hormonal profile and sexual dysfunction severity between positive and negative drug abuse groups. To identify predictors for positive drug abuse result in urine testing, binary logistic regression was done using the smoking, history of drug abuse and occupation (driver) variables. It showed that both smoking $(\mathrm{OR}=22.39,95 \% \mathrm{CI}: 4.20-119.19, \mathrm{p}=<0.0001)$, and history of drug abuse $(\mathrm{OR}=20.26,95 \% \mathrm{CI}: 5.21-78.76, \mathrm{p}=<0.0001)$ are significantly independent predictors for positive drug abuse test as shown in Table (2).

Table 2: The result of the binary logistic regression to identify positive drug abuse urine testing using the smoking, history of drug abuse and occupation (driver) variables.

\begin{tabular}{|c|c|c|c|c|c|c|c|c|}
\hline \multirow[t]{2}{*}{ Variable } & \multirow[t]{2}{*}{ B } & \multirow[t]{2}{*}{ S.E. } & \multirow[t]{2}{*}{ Wald } & \multirow[t]{2}{*}{ df } & \multirow[t]{2}{*}{ Sig. } & \multirow[t]{2}{*}{$\begin{array}{l}\text { Exp } \\
\text { (B) }\end{array}$} & \multicolumn{2}{|c|}{$\begin{array}{l}95 \% \text { C.I. } \\
\text { for } \operatorname{EXP(B)}\end{array}$} \\
\hline & & & & & & & Lower & Upper \\
\hline Smoking & 3.109 & .853 & 13.279 & 1 & .000 & 22.39 & 4.207 & 119.190 \\
\hline History of drug abuse & 3.009 & .693 & 18.867 & 1 & .000 & 20.26 & 5.213 & 78.761 \\
\hline Occupation (Driver) & 1.018 & 1.198 & .721 & 1 & .396 & 2.767 & .264 & 28.971 \\
\hline
\end{tabular}

Patients were classified into 2 groups: negative drug abuse $(n=65)$ and positive drug abuse $(n=35)$. All variables were compared between the two groups as shown in 
SOHAG MEDICAL JOURNAL Causative Relationship Between Drug Abuse And

Vol. 22 No.2 July 2018

Mohammed H. Mohammed

Table (3). Patients classification according the result of drug abuse $(n=100)$.

$\mathrm{SD}=$ Standard deviation; $\mathrm{THC}=$ Tetrahydrocannabinol; $\mathrm{BM} \mathrm{I}=$ body mass index; $\mathrm{LH}=$ luteinizing hormone;

\begin{tabular}{|c|c|c|c|c|}
\hline \multicolumn{2}{|c|}{ Parameter } & $\begin{array}{l}\text { Negative } \\
\text { drug abuse } \\
n=65 \\
\text { Mean } \pm \text { SD/ Median }\left(25^{\text {th }}-75^{\text {th }}\right) \text { or percentage }\end{array}$ & \multirow[t]{2}{*}{$\begin{array}{l}\text { Positive } \\
\text { drug abuse } \\
\mathbf{n}=35 \\
\begin{array}{l}\text { Mean } \pm \text { SD/ Median } \quad\left(25^{\text {th }}-75^{\text {th }}\right) \quad \text { or } \\
\text { percentage }\end{array}\end{array}$} & \multirow[t]{2}{*}{ P Value } \\
\hline \multicolumn{3}{|c|}{ History: } & & \\
\hline \multicolumn{2}{|c|}{ Age (Years) } & $40(31-47)$ & $39(33-34)$ & $0.553 \#$ \\
\hline \multicolumn{2}{|c|}{ Smoking (\%) } & $19 \%$ & $33 \%$ & $*<0.0001 \mathrm{~d}$ \\
\hline \multicolumn{2}{|c|}{$\begin{array}{ll} & \begin{array}{l}\text { Smoking history } \\
\text { (years) }\end{array}\end{array}$} & $16(10-20)$ & $14(12-20)$ & $0.894 \#$ \\
\hline \multicolumn{2}{|c|}{ Cigarette/day } & $25(15-40)$ & $20(15-30)$ & $0.367 \#$ \\
\hline$\bullet$ & $\begin{array}{l}\text { Brinkman smoking } \\
\text { index }\end{array}$ & $330(200-560)$ & $300(205-410)$ & $0.562 \#$ \\
\hline \multicolumn{2}{|c|}{$\begin{array}{l}\text { Occupation: } \\
\text { Manual } \\
\text { worker/farmer }\end{array}$} & $\begin{array}{l}34 \% \\
26 \% \\
5 \%\end{array}$ & $\begin{array}{l}19 \% \\
7 \% \\
9 \%\end{array}$ & $* 0.018$ पा \\
\hline \multicolumn{2}{|c|}{$\begin{array}{l}-\quad \text { Employee } \\
\text { - } \quad \text { Driver } \\
\text { Sexual history: }\end{array}$} & & & \\
\hline \multicolumn{2}{|c|}{ Marriage duration (years) } & $11(4-16)$ & $10(6-15)$ & $0.983 \#$ \\
\hline \multicolumn{5}{|c|}{ Patients sexual complaint: } \\
\hline$\bullet$ & $\begin{array}{l}\text { Desire } \\
\text { problem } \\
\text { complaint }\end{array}$ & $4 \%$ & $3 \%$ & 0.651 II \\
\hline$\bullet$ & $\begin{array}{l}\text { Erectile } \\
\text { dysfunction } \\
\text { complaint }\end{array}$ & $36 \%$ & $21 \%$ & $0.657 \mathrm{qI}$ \\
\hline$\bullet$ & $\begin{array}{l}\text { Premature } \\
\text { ejaculation } \\
\text { complaint }\end{array}$ & $50 \%$ & $26 \%$ & $0.768 \mathrm{gI}$ \\
\hline$\bullet$ & $\begin{array}{l}\text { Orgasmic } \\
\text { disorder } \\
\text { complaint }\end{array}$ & $11 \%$ & $6 \%$ & 0.978 II \\
\hline 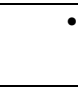 & $\begin{array}{l}\text { Mixed } \\
\text { sexualdysfunc } \\
\text { tion complaint }\end{array}$ & $27 \%$ & $16 \%$ & $0.687 \mathrm{qI}$ \\
\hline $\begin{array}{l}\text { Sexual } \\
\text { (month }\end{array}$ & $\begin{array}{l}\text { complaint duration } \\
\text { hs) }\end{array}$ & $10(8-17)$ & $12(7-20)$ & $0.373 \#$ \\
\hline $\begin{array}{l}\text { Freque } \\
\text { interco }\end{array}$ & $\begin{array}{l}\text { ency of } \\
\text { uurse/week }\end{array}$ & $2(2-3)$ & $2(2-3)$ & $0.825 \#$ \\
\hline Wife ag & ge (years) & $33.71 \pm 8$ & $32.51 \pm 6.4$ & $0.419 \S$ \\
\hline \multicolumn{5}{|c|}{ Drug abuse history : } \\
\hline \multicolumn{2}{|c|}{$\begin{array}{l}\text { Positive drug abuse } \\
\text { history }\end{array}$} & $12 \%$ & $31 \%$ & $*<0.0001 \mathrm{II}$ \\
\hline \multicolumn{2}{|c|}{ Drug abuse duration (yrs) } & $3(2.25-4.75)$ & $5(3-7.75)$ & $0.056 \#$ \\
\hline \multicolumn{2}{|c|}{$\begin{aligned} \text { Route of drug } \\
\text { administration: } \\
\bullet \quad \text { Oral } \\
\bullet \quad \text { Inhalation } \\
\bullet \quad \begin{array}{l}\text { Oral/Inhalatio } \\
\text { n }\end{array}\end{aligned}$} & $\begin{array}{l}9 \% \\
3 \% \\
0 \%\end{array}$ & $\begin{array}{l}14 \% \\
7 \% \\
9 \%\end{array}$ & 0.088 qा \\
\hline \multicolumn{5}{|c|}{ General examination: } \\
\hline \multicolumn{2}{|c|}{ Weight (Kg) } & $80.56 \pm 7.65$ & $76.4 \pm 13.93$ & $0.479 \S$ \\
\hline \multicolumn{2}{|c|}{ Height (M) } & $1.68 \pm 0.03$ & $1.65 \pm 0.08$ & $0.366 \S$ \\
\hline \multicolumn{2}{|c|}{ BMI $\left(\mathrm{Kg} / \mathrm{m}^{2}\right)$} & $23.96 \pm 2.12$ & $23.03 \pm 2.92$ & $0.505 \S$ \\
\hline \multicolumn{5}{|c|}{ Hormonal profile: } \\
\hline \multicolumn{2}{|c|}{$\begin{array}{ll}\cdot & \text { Total testosterone } \\
\text { (TT) }(\mathrm{ng} / \mathrm{ml})\end{array}$} & $6.32(3.08-7.66)$ & $6.24(2.39-7.4)$ & $0.501 \#$ \\
\hline \multicolumn{2}{|r|}{ LH (mIU/ml) } & $3.23(2.05-5.02)$ & $3.1(2.1-4.2)$ & $0.963 \#$ \\
\hline$\bullet$ & FSH $(\mathrm{mIU} / \mathrm{ml})$ & $2.9(1.87-4.62)$ & $4.21(1.85-5.6)$ & $0.404 \#$ \\
\hline \multicolumn{5}{|c|}{ Sexual function evaluation: } \\
\hline \multicolumn{2}{|c|}{ SHIM score } & $15(11-20)$ & $15(12-19)$ & $0.742 \#$ \\
\hline \multicolumn{2}{|l|}{ EHS } & $3(2-3)$ & $3(2-3)$ & $0.756 \#$ \\
\hline \multicolumn{2}{|l|}{ AIPE } & $19(16-24)$ & $20(16-25)$ & $0.653 \#$ \\
\hline
\end{tabular}

FSH=follicle stimulating hormone, SHIM =sexual health inventory for men, EHS=erection hardness score, AIPE=Arabic index of premature ejaculation 


\section{Discussion}

Most of the current literatures support that drug abuse has a negative influence on sexual functions although lack of clear underlying mechanisms (Zaazaa A.et al, 2013). This negative influence could not be reversed immediately by stopping the drug abuse (Vallejo-medina p.et a, 2013). The present study is the first study that tries to evaluate drug abuse among male patients with sexual dysfunctions in Upper Egypt. In the current study, drug abuse in male patients with sexual dysfunction was 35\% (35/100); with the most common drug was tramadol $19 \%(19 / 100)$ followed by THC (Cannabis) 12\% (12/100). The higher prevalence of Tramadol in the current study could be due to the higher proportion of patients with $\mathrm{PE}$ in the studied population 76\% (76/100), which makes PE patients abusing tramadol to control their ejaculation as tramadol exhibit efficacy in controlling ejaculation(Abdel- Hamid IA. et al,2016).

Tramadol is mainly an opioid receptor agonist with some monoaminergic reuptake inhibitory activity. It is used in acute and chronic pain therapy; however its abrupt cessation increases the incidence of withdrawal symptoms (Miotto K. et al, 2017).

It is usually assumed that there is a great difference in the prevalence and pattern of drug abuse studies due to different study groups and different methodologies (WHO, 2010). Tramadol abuse was $8.8 \%$ (18/204) among Egyptian school students (13-18 years old), and high association with smoking was found (BassionyMM.et al ,2015).This was lower than the current study result. It could seem that tramadol abuse is increased with age as the prevalence was $19 \%(19 / 100)$ in patients aged 39 (31-45) years old.
However, a large community survey in Egypt involving 44,000 subjects using a questionnaire derived from the Addiction Severity Index (ASI) showed the drug abuse lifetime prevalence was $7.2-14.5 \%$, with the cannabis was the commonest drug followed by alcohol (Hamdi E. et al, 2013).

For testing drug abuse, different specimens can be obtained including body fluids like urine, blood, saliva, and sweat. Other specimens can be obtained from hair, breath and meconium. These different specimens exhibit different detection windows for drug abuse due to different rates and durations of excretion. Urine testing for drug abuse has a short to intermediate window of detection (up to 30 days). However, these rapid urine tests lack specificity and should be confirmed by specific antibodies (Hadland SE.et al, 2016).

In the current study, smoking was significantly higher in positive drug abuse patients with sexual dysfunction. This was found also among Egyptian adolescent students. The relationship between drug abuse especially tramadol and smoking is bidirectional. The smoking increases tramadol abuse and tramadol abuse increases the nicotine dependence (Bassiony MM. et al, 2018) .Smoking was considered independent predictor for positive drug abuse testing in the current study. So smoking could be a gateway for drug abuse (Lai S.et al, 2000).Based on this finding, reducing the smoking could be a possible solution for controlling drug abuse problem.

There were no significant changes in the hormonal profile between positive and negative drug abuse groups. However, 
another study evaluated opioid dependent patients $(n=30)$ and found low testosterone with high prolactin and LH(Abdelazim S. et al, 2015). This difference may be due to that patients in the current study were not drug dependent as in this study. Also, the lower number of patient in this study is another limitation of its result.

In the current study, there were no significant changes of type and/ or severity of sexual dysfunction between positive and negative drug abuse groups. This could be due to small sample size of the study. However, sexual dysfunction could be one of the important reasons to start drug abuse as some patients believe that drug abuse could improve their sexuality problem. Therefore, the drug abuse prevalence has been increased with increased sexual dysfunction severity (Lapera G. et al, 2008). Because of the close relationship between drug abuse and sexuality in the concept of the patients with sexual dysfunction; they usually declare their drug abuse history when discussing their sexual problems with physician. This could explain the present findings in the current study that drug abuse history is independent predictor for positive drug abuse test in patients with sexual dysfunction.

Other reasons of drug abuse in addition to sexual improvement could include relaxation, being intoxicated, being awake at night, and enhancing a specific activity. It must be noted that men with drug abuse have more risky sexual behaviors including anal intercourse, less condom use, and having sex with casual partner (Calsyn DA. et al, 2010). However, the link between sex under the influence of drug and sexual risk behavior has not been supported in heterosexual men in another study (Calsyn DA. et al, 2011). The study has several limitations. The sample size was limited. The cost of drug abuse testing was the main limiting factor. Also, it could not recruit healthy volunteers who can represent the general population. So a comparison between patients with sexual dysfunction and healthy control could not be done. In addition, results of drug abuse testing were confirmed by drug analyzer which is qualitative to denote the presence or absence of the drug, but no concentration for the drug was measured. Therefore, a large sample sized study with healthy control is recommended.

\section{Conclusions:}

Drug abuse is prevalent among Egyptian male patients with sexual dysfunction, especially tramadol. The drug abuse is common among smoker, and driver occupation. However, no hormonal disturbance could be shown in drug abuse patients. More patient awareness and legal regulations should be considered to reduce drug abuse in Egypt.

\section{References}

[1] World Health Organization. ATLAS on substance use: resources for the prevention and treatment of substance use disorders. Geneva:( 2010).

[2] Loffredo CA, Boulos DN, Saleh DA, et al. Substance use by Egyptian youth: current patterns and potential avenues for prevention. Substance use \& Misuse. 2015;50: 609-18.

[3] Kumsar NA, Kumsar Ş, Dilbaz N. Sexual dysfunction in men diagnosed as substance use disorder. Andrologia. 2016;48: 1229-35.

[4]Zaazaa A, Bella AJ, Shamloul R. Drug addiction and sexual dysfunction. Endocrinology and Metabolism Clinics of North America. 2013;42: 585-92.

[5] Ajo R, Segura A, Inda MM, et al. Opioids Increase Sexual Dysfunction in Patients With Non-Cancer Pain. The Journal of Sexual Medicine. 2016;13: 1377-86.

[6] Shamloul R, Bella AJ. Impact of cannabis use on male sexual health. 
The Journal of Sexual Medicine. 2011;8: 971-5.

[7] Shamloul R, Ghanem H, Abou-zeid A. Validity of the Arabic version of the sexual health inventory for men among Egyptians. International Journal of Impotence Research. 2004;16: 452-5.

[8] Arafa M, Shamloul R. The Arabic version of the Erection Hardness Score. The Journal of Sexual Medicine. 2009;6: 3501-3.

[9] Arafa M, Shamloul R. Development and evaluation of the Arabic Index of Premature Ejaculation (AIPE). The Journal of Sexual Medicine. 2007;4: 1750-6.

[10] Vallejo-Medina P, Sierra JC. Effect of drug use and influence of abstinence on sexual functioning in a Spanish male drug-dependent sample: a multisite study. The Journal of Sexual Medicine. 2013;10: 333-41.

[11] Abdel-Hamid IA, Andersson KE, Waldinger MD, Anis TH. Tramadol Abuse and Sexual Function. Sex Med Rev. 2016;4: 235-46.

[12] Miotto K, Cho AK, Khalil MA, Blanco K, Sasaki JD, Rawson R. Trends in Tramadol: Pharmacology, Metabolism, and Misuse. Anesthesia and Analgesia. 2017;124: 44-51.

[13] Bassiony MM, Salah El-Deen GM, Yousef U, et al. Adolescent tramadol use and abuse in Egypt. The American Journal of Drug and Alcohol Abuse. 2015;41: 206-11.

[14] Hamdi E, Gawad T, Khoweiled A, et al. Lifetime prevalence of alcohol and substance use in Egypt: a community survey. Substance Abuse. 2013;34: 97-104.
[15] Hadland SE, Levy S. Objective Testing: Urine and Other Drug Tests. Child and Adolescent Psychiatric Clinics of North America. 2016;25: 549-65.

[16] Bassiony MM, Abdelghani M, Salah El-Deen GM, Hassan MS, ElGohari H, Youssef UM. Opioid Use Disorders Attributed to Tramadol Among Egyptian University Students. Journal of Addiction Medicine. 2018;12: 150-55.

[17] Lai S, Lai H, Page JB, McCoy CB. The association between cigarette smoking and drug abuse in the United States. Journal of Addictive Diseases. 2000;19: 11-24.

[18] Abdelazim S, Abolmagd SF, Abdalla H, Enaba DA, Elsheikh SM, Moselhy HF. Sexual Dysfunction and Sex Hormone Levels in Egyptian Opioid-Dependent Males American Journal of Pharmacy \& Health Research. 2015;3: 81-91.

[19] La Pera G, Carderi A, Marianantoni Z, Peris F, Lentini M, Taggi F. Sexual dysfunction prior to first drug use among former drug addicts and its possible causal meaning on drug addiction: preliminary results. The Journal of Sexual Medicine. 2008;5: 164-72.

[20] Calsyn DA, Baldwin H, Niu X, Crits-

Christoph P, Hatch-Maillette MA. Sexual risk behavior and sex under the influence: an event analysis of men in substance abuse treatment who have sex with women. The American Journal on Addictions. 2011;20: 250-6. 